\title{
Laboratory Diagnosis of Lupus Anticoagulants
}

\author{
DOUGLAS A. TRIPLETT, M.D., F.A.C.P.
}

Circulating anticoagulants or inhibitors of clotting factors are defined as endogenously produced substances that interfere with various in vitro tests of coagulation. ${ }^{1}$ Anticoagulants are usually immunoglobulins, although other endogenous materials, such as heparin or fibrinogen split products, may inhibit in vivo or in vitro coagulation (Table 1). Specific inhibitors are immunoglobulins with epitope specificity for a single coagulation protein. These inhibitors may be neutralizing or nonneutralizing. ${ }^{2,3}$ The most common specific inhibitors are auto or alloantibodies to Factor VIII. ${ }^{4}$ It is imperative to identify correctly Factor VIII inhibitors, since they are associated with significant clinical bleeding. ${ }^{1}$ Nonspecific inhibitors, such as lupus anticoagulants (LA) are not directed at any single coagulation protein and they are generally not associated with bleeding. ${ }^{5}$

Conley and Hartmann ${ }^{6}$ first reported an association between circulating anticoagulants and systemic lupus erythematosus (SLE). ${ }^{6}$ Their first case report emphasized a correlation with bleeding; however, subsequent studies have shown that these patients generally do not have a bleeding tendency attributable to the coagulation inhibitor. The term "lupus anticoagulant" was suggested in 1972 by Feinstein and Rapaport. ${ }^{7}$ It is, however, an unfortunate misnomer, since the majority of patients do not have SLE and, in the absence of other hemostatic abnormalities, the patients do not bleed.

Since patients with LA generally lack hemorrhagic symptoms, clinicians and laboratories initially regarded LA as a nuisance. However, laboratories were required to investigate the causes of abnormal activated partial thromboplastin times (APTT). Often the evaluation of the abnormal APTT involved multiple factor assays and time-consuming mixing studies yielded inconclusive or

From the Department of Pathology, Indiana University School of Medicine, and Department of Hematology, Ball Memorial Hospital, Muncie, Indiana.

Reprint requests: Dr. Triplett, Department of Hematology, Ball Memorial Hospital, Muncie, IN 47303. confusing results. Thus, some reagent manufacturers designed their reagents to be insensitive to the presence of LA.

Paradoxically, LA was subsequently found to be associated with both arterial and venous thrombosis as well as recurrent pregnancy loss. ${ }^{3.8 .9}$ Consequently, laboratories are now receiving requests to evaluate patients for the presence of LA. This review will focus on the characterization, clinical associations, and laboratory diagnosis of LA.

\section{CHARACTERIZATION OF LUPUS ANTICOAGULANTS}

LAs are immunoglobulins (usually IgG, occasionally $\operatorname{IgM}, \operatorname{IgA}$, or a mixture) that interfere with in vitro phospholipid-dependent coagulation tests, such as prothrombin time (PT), APTT, and dilute Russell's viper venom time (dRVVT). ${ }^{1.7}$ These antibodies do not specifically inhibit any of the coagulation factors; rather, they appear to be directed at phospholipid epitopes. ${ }^{5}$ Early case reports of LA often noted an association with biologic false-positive tests for syphilis or abnormal flocculation tests of liver function. Laurell and Nilsson ${ }^{10}$ found cardiolipin used in the VDRL test system would partially adsorb LA from plasma. Thiagarajan et al ${ }^{11}$ subsequently isolated an IgM monoclonal LA from a patient with Waldenström's macroglobulinemia. This monoclonal LA reacted with anionic phospholipids but did not prevent in vitro platelet-dependent prothrombinase activity. However, when phospholipid micelles were substituted for platelets, in vitro coagulation reactions were inhibited. These observations further established the phospholipid specificity of LA and also provided insight into the lack of clinical bleeding.

Although it is now clear the LAs react with phospholipids, the precise epitope or epitopes with which LAs react are poorly understood. Harris et $\mathrm{al}^{12}$ have demonstrated a close relationship between LA and anti- 
TABLE 1. Classification of Circulating Anticoagulants*

Specific

$\begin{array}{lc}\text { Neutralizing } & \text { Non-neutralizing } \\ \text { Factor V } & \text { Factor VIII } \\ \text { Factor VIII } & \text { von Willebrand's factor } \\ \text { Factor IX } & \text { Prothrombin } \\ \text { Factor XI } & \text { Factor X } \\ \text { Factor XIII } & \\ \text { von Willebrand's factor } & \\ \text { Lupus cogenticoagulants- } & \\ \text { anticoagulants } & \\ \text { Paraproteins } & \\ \text { Fibrin split products } \dagger & \\ \text { Heparin-like activity } & \end{array}$

Global Heparin-like activity

* From Triplett and Brandt. ${ }^{77}$ Reprinted with permission. $\dagger$ As originally defined: Fibrinogen degradation products (FDP).

cardiolipin antibodies (ACA). However, other investigators have not found the same degree of concordance. ${ }^{13,14}$ Some monoclonal antibodies with LA activity cross-react with DNA and cardiolipin. ${ }^{15}$ These findings suggest that DNA and phospholipids share a common epitope that reacts with LA. The regularly spaced phosphodiester groups found in both DNA and phospholipids were initially proposed as the putative epitope. However, the inability of LA to bind to neutral phospholipids, such as phosphatidylcholine (PC), phosphatidylethanolamine (PE) would suggest another epitope. ${ }^{16}$

Janoff and Rauch ${ }^{17}$ have approached the question of LA specificity using monoclonal hybridoma LA antibodies derived from patients with SLE. These antibodies were selected based on their ability to prolong a dilute APTT. Initially, the monoclonal LAs were evaluated using various phospholipids to inhibit the LA in the APTT test system. ${ }^{18}$ These experiments required incubation of the LA with phospholipids prior to adding the mixture to the APTT assay. They found PE inhibited the LA activity, whereas PC and phosphatidylinositol (PI) did not. Thus, these results were divergent from the studies of Thiagarajan et al. ${ }^{11}$ Further studies by Rauch et al ${ }^{18}$ suggested that LAs react with lipids that assume a hexagonal configuration at $37^{\circ} \mathrm{C}$.

Hexagonal phospholipid configurations can occur in vivo with membrane damage. ${ }^{19,20}$ Thus, LA may represent antibodies produced in response to an altered membrane phospholipid configuration secondary to injury (such as viral, drugs, tumor necrosis factor).

\section{CLINICAL CORRELATIONS}

LA may be identified in a variety of clinical conditions, including autoimmune disorders, as a result of certain medications, following infections, and malignancies (Table 2).

In most general laboratory settings, LAs are detected serendipitously as a result of routine laboratory screening. The reported prevalence in unscreened general populations or in preselected diseases such as SLE has varied widely. ${ }^{21}$ This variability is due to patient selection, as well as test sensitivity and specificity. Also, the diligence of the technologists performing the assay is critical in identification of LA. LAs are often transient and, considering their association with infectious diseases, probably occur at one time or another in a significant percentage of apparently normal persons of all ages.

The incidence of LA in autoimmune diseases has been most thoroughly evaluated in SLE. Early studies suggested an incidence of approximately $10 \% ;^{22,23}$ however, more recent studies have reported values of 21 to $65 \% .{ }^{24}$ Patient selection, disease activity, criteria for the laboratory diagnosis, and treatment all contribute to these differences.

Drug-induced LAs have been reported with hydralazine, chlorpromazine, quinidine, and procainamide; these drugs have all been implicated in drug-induced SLE-like syndromes. Other drugs associated with LA include various antibotics and phenytoin. ${ }^{25}$ In four large series of patients with LA, drug-associated LA was identified in $6 \%$ (14 of 219 ), ${ }^{26} 34 \%$ (34 of 100), $4 \%$ ( 4 of $100),{ }^{27}$ and $15 \%$ (5 of 33 ). ${ }^{28}$ Drug-related LAs have been most frequently reported with chlorpromazine and procainamide. ${ }^{29,30}$ In a series of 47 patients receiving

TABLE 2. Clinical Conditions Associated with Lupus Anticoagulants*

\begin{tabular}{l}
\hline Autoimmune diseases \\
Systemic lupus erythematosus \\
Rheumatoid arthritis \\
Others, including "overlap", syndromes \\
Drug exposure \\
Chlorpromazine \\
Procainamide \\
Hydralazine \\
Quinidine \\
Antibiotics \\
Phenytoin \\
Infections \\
Bacterial \\
Protozoan (Pneumocystis carinii) \\
Viral (HIV-1) \\
Fungal \\
Lymphoproliferative disorders \\
Hairy cell leukemia \\
Malignant lymphoma \\
Waldenström's macroglobulinemia \\
Miscellaneous disorders \\
Epithelial malignancies \\
No underlying diseases \\
* From Triplett and Brandt. \\
\end{tabular} 
chlorpromazine for longer than $2 \frac{1}{2}$ years, 41 developed LA. Most drug-related LAs have been IgM. ${ }^{29,31} \mathrm{Al}-$ though early reports indicated no thrombotic predisposition in patients with drug-related LAs, more recent studies have found an incidence similar to other LA patients. ${ }^{13}$

Most transient LAs are seen in the setting of infectious diseases. ${ }^{25,32}$ Often, LAs are detected in children as the result of a preoperative coagulation screen prior to tonsillectomy and adenoidectomy. LAs have also been identified in patients with the acquired immune deficiency syndrome (AIDS) (Table 3). ${ }^{33-36}$

The associated infections may be protozoan, viral, fungal, or bacterial. With successful treatment of the infectious disease, the LA will usually disappear. ${ }^{37} \mathrm{ACA}$ have also been found in patients with AIDS. ${ }^{38}$ Familial cases of LA have been reported. ${ }^{39,40}$ In a significant percentage of LA cases, no underlying disease is identified.

\section{CLINICAL COMPLICATIONS ASSOCIATED WITH LUPUS ANTICOAGULANTS}

The identification of LA or antiphospholipid antibodies (APA) has received increased attention due to the association between these antibodies and a variety of clinical complications.

The paradoxical occurrence of thromboembolic events in patients with in vitro hypocoagulable plasma remains an intriguing and important, although as yet, unexplained observation. LA/APA have also been associated with spontaneous abortion, fetal death, and a variety of other obstetric complications ${ }^{1-3}$ (Table 4). LA/ APA have also been implicated as a cause of infertility. ${ }^{41}$

\section{Thromboembolic Complications}

Bowie et $\mathrm{al}^{8}$ were the first to report an increased risk of thrombosis in patients with LA. The cumulative literature suggests approximately $30 \%$ of patients with LA will have at least one thrombotic event. ${ }^{42}$ Unlike hered-

TABLE 3. Lupus Anticoagulant and AIDS*

\begin{tabular}{|c|c|c|c|c|}
\hline Author & No. Patients & $L A$ & Immunoglobulin & Infections \\
\hline Le Frere et $\mathrm{al}^{33}$ & 25 & 13 & - & $10 / 13$ \\
\hline Bloom et $\mathrm{al}^{34}$ & 38 & 28 & - & - \\
\hline Cohen et $\mathrm{al}^{35}$ & 50 & 10 & 6/7 IgM & $9 / 10$ \\
\hline Gold Zalusky $^{36}$ & $\underline{52}$ & $\underline{26}$ & - & $25 / 26$ \\
\hline Total & 165 & $77(47 \%)$ & & \\
\hline
\end{tabular}

* LA was often transient.
TABLE 4. Obstetric Complications Associated with Lupus Anticoagulants

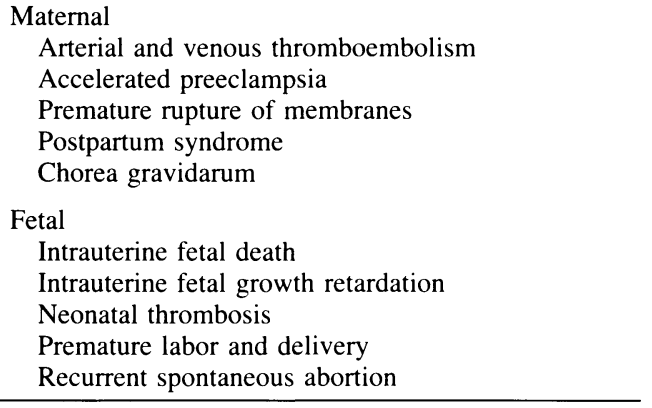

itary deficiencies of antithrombin III, protein C, and protein S, patients with LA have both arterial and venous thrombosis. ${ }^{2,43,44}$

The arterial thrombi most often involve the cerebral vessels with clinical presentation as strokes, transient ischemic attacks, and amaurosis fugax.$^{45}$ Histologically, the involved arteries and veins are characterized by bland thrombosis with no evidence of vessel wall inflammation.

Whether LAs are involved in the pathogenesis of the thrombotic episodes or merely represent an epiphenomenon is currently unresolved. The frequency of thrombosis seen in association with LA is perhaps skewed due to selection biases. The presence of LA in patients with SLE appears to identify a subset of patients with a three- to four-fold increased incidence of thrombosis. Often, the LA may appear years before the first thrombotic episode. In order to resolve the role of LA in thrombosis, there is a need for a well-designed prospective study to evaluate a broad spectrum of patients with LA.

A variety of potential pathophysiologic mechanisms have been proposed to explain the association of LA and thrombosis. Carreras et $\mathrm{al}^{46}$ first suggested LA may prevent the mobilization of arachidonic acid from endothelial cell membranes resulting in decreased prostacyclin $\left(\mathrm{PGI}_{2}\right)$ production ${ }^{46}$. Since $\mathrm{PGI}_{2}$ is a potent inhibitor of platelet aggregation, decreased amounts of $\mathrm{PGI}_{2}$ may potentially contribute to thrombosis. These original studies were carried out using heterologous systems (human plasma and rat aortic endothelium). Subsequent studies using homologous in vitro experiments have yielded conflicting results. ${ }^{47,48}$

Other hypotheses have focused on abnormal fibrinolysis, platelet activation, and abnormal antithrombin III activity. ${ }^{49-51}$ Perhaps the most promising investigations have focused on the interaction of LA and endothelial cells. Endothelial cells may express both anticoagulant and procoagulant properties. Under physiologic conditions, the anticoagulant properties are predominant. 
Several groups have now demonstrated the ability of LA to interfere with the activation of protein $\mathrm{C}$ by the thrombin-thrombomodulin complex. ${ }^{52-55}$ The activation of protein $\mathrm{C}$ is a calcium ion, phospholipid-dependent reaction that occurs in vivo on the endothelial surface. Activated protein $\mathrm{C}$ is an important regulatory protein that preferentially degrades activated forms of the cofactors V and VIII. Decreased protein C activity is associated with clinical venous and rarely arterial thrombosis. Additional studies are needed to evaluate this potential mechanism of LA-induced thrombosis further.

A variety of substances, including tumor necrosis factor, interleukin 1, and endotoxin, may induce endothelial cell production of tissue factor (TF). TF is a lipoprotein that is the cofactor for the extrinsic pathway of Factor X activation. Recently, Rustin and colleagues ${ }^{48}$ studied sera from patients with SLE in an experiment designed to evaluate the expression of cultured endothelial cell procoagulant activity. Using a two-stage coagulation assay, SLE sera caused an increase in procoagulant activity. The expression of TF by endothelial cells required de novo synthesis of protein. Perhaps the increased $\mathrm{TF}$ found in these experiments may be explained by antibody binding to endothelial cells, with resulting membrane perturbation and subsequent TF production. ${ }^{56}$

\section{Obstetric Complications}

Nilsson and colleagues ${ }^{9}$ were the first to describe an association between recurrent abortions and LA. Soulier and Boffa ${ }^{57}$ subsequently described the triad of LA, recurrent abortions, and thrombosis. ${ }^{57}$ Since these first reports, several additional retrospective studies have confirmed the clinical syndrome of repeated abortions with LA or ACA. ${ }^{58-61}$ Most commonly, the women will have a history of first trimester abortion or second trimester fetal death. The initial reports stressed the presence of placental infarction as the cause of fetal loss. ${ }^{62}$ However, in many cases the degree of placental impairment due to the infarction appears to be insufficient to account for fetal death. ${ }^{60}$ Decreased $\mathrm{PGI}_{2}$ production by fetal and maternal tissues has also been suggested as an explanation for fetal loss. ${ }^{59}$ The pattern of decreased $\mathrm{PGI}_{2}$ production in women with LA is similar to that seen in preeclampsia. ${ }^{63}$ Studies that have evaluated LA in women with histories of recurrent abortions have found an incidence varying from 5.2 to $48 \%{ }^{64-66}$

\section{Thrombocytopenia}

Thrombocytopenia is also associated with LA. In patients with SLE, thrombocytopenia is seen in the LApositive group with an incidence of 50 to $60 \% .^{67,68} \mathrm{In}$ contrast, $25 \%$ of the SLE/LA-negative patients have a complicating thrombocytopenia. ${ }^{69}$ Other patient groups with LA have varying degrees of thrombocytopenia.

\section{Cutaneous Manifestations}

Cutaneous manifestations associated with LA range from livedo reticularis to widespread cutaneous necrosis. ${ }^{70-72}$ Livedo reticularis is a clinical finding closely linked to ACA and LA. LAs have also been described in patients with Degos' disease and Behçet's syndrome. ${ }^{73}$ Both of these conditions are associated with thrombotic complications.

\section{Bleeding Complications Associated with Lupus Anticoagulants}

Although the presence of LA alone is not associated with bleeding, a number of concomitant abnormalities may predispose the patient to hemorrhage (Table 5).

Occasionally, patients with LA may have a specific coagulation inhibitor, such as Factor VIII antibody. Antibodies to Factor VIII may be particularly difficult to identify in a patient with a LA. This situation may arise in patients with autoimmune diseases (SLE), with hemophilia A, or complicating AIDS with a LA. ${ }^{74}$ Factors $\mathrm{V}$ and XI inhibitors may be very difficult to separate from a LA. Therefore specific factor assays are necessary in patients with an apparent LA and associated clinical hemorrhage. Acquired prothrombin deficiency is also associated with $\mathrm{LA}^{75}$

\section{LABORATORY IDENTIFICATION OF LUPUS ANTICOAGULANTS}

Although the Working Party on Acquired Inhibitors of Coagulation of the International Committee on Thrombosis and Haemostasis proposed a set of criteria to diagnose LA, these criteria have not been widely accepted. ${ }^{76}$ The lack of acceptance is no doubt due to the reliance on one- and two-stage factor assays. Factor assays are expensive and two-stage factor assays are not widely used in routine laboratories. Triplett and $\mathrm{Brandt}^{77}$ have re-

\section{TABLE 5. Potential Causes of Bleeding in Patients with Lupus Anticoagulants}

\footnotetext{
Specific factor inhibitors

Factor VIII inhibitors

Factor II inhibitors

Thrombocytopenia

Platelet dysfunction

Uremia

Concomitant drug administration (aspirin)
} 
cently proposed minimal criteria that incorporate the concept of phospholipid specificity of LA. These criteria are: (1) an abnormality of a phospholipid-dependent coagulation test (in most instances this will be an unexplained abnormal APTT); (2) demonstration that the abnormality is due to an inhibitor; and (3) proof that the inhibitor is directed at phospholipids.

The laboratory approach to the diagnosis of LA may be staged according to the criteria just mentioned. Screening procedures will usually identify an unexplained prolongation of the APTT or PT. In many instances the findings of an abnormal APTT are the result of a routine coagulation screen. Once an abnormal APTT is found, the next step is mixing studies to establish the presence of an inhibitor. The final step in the evaluation requires confirmatory procedures to identify phospholipid specificity of the inhibitor.

Although historically the identification of LA was usually a serendipitous finding, there has been a dramatic change within the last 5 years. This change is secondary to the identification of LA-associated clinical findings of abortion and recurrent thrombosis and the concept of the phospholipid antibody syndrome, which broadens the laboratory diagnosis to include immunologic procedures to identify APA ${ }^{78}$ Consequently, many laboratories are now being asked: "Does this patient have a lupus anticoagulant?" Thus, the laboratory must develop a systematic approach to this question rather than the historical reactive approach to an unexplained coagulation result.

\section{Preanalytic Variables}

Perhaps the most important step in the evaluation of patient samples for LA involves careful specimen collection and processing. The centrifugation step is critical, since the ability of coagulation assays to detect LA is generally inversely proportional to the number of platelets in the platelet-poor plasma (PPP) ${ }^{79}$ Careful preparation of PPP will also improve the stability of frozen samples; PPP with significant residual platelets will have considerable shortening of a prolonged APTT on freezethawing. ${ }^{80}$ Millipore-filtered plasma and the commercially available serum-plasma separators will yield excellent PPP. ${ }^{79}$

\section{Screening Procedures}

A variety of tests have been used to screen for the presence of LA. In the vast majority of laboratories the APTT is used for this purpose. The popularity of the APTT is due to its commercial availability, ease of automation, and simplicity. Although there is wide variation in sensitivity to LA, when a sensitive and responsive reagent is used, the APTT performs as well if not better than other test systems (such as dRVVT, kaolin clotting time (KCT), and plasma clot time (PCT) ${ }^{81-84}$ The differing sensitivity of APTT reagents is due to a number of variables, including amount, composition, and configuration of phospholipid, surface activator, and other properties, such as buffering capacity. Also the marked heterogeneity of LA from patient to patient should be emphasized. No single test system or reagent will identify all patients with LA.

The KCT is commonly used as a screening procedure for LA in Europe and Australia. ${ }^{85}$ The KCT is performed on PPP with no added phospholipids. Exner et $\mathrm{al}^{85}$ have described several patterns of KCT when plasma samples containing LA were mixed with varying amounts of normal plasma. ${ }^{85}$ The major disadvantage of the KCT is an inability to be automated. Based on limited studies, the KCT appears to be the most sensitive test for detecting LA in the setting of pregnancy.

\section{Identification of Inhibitor Activity}

Once an abnormal screening procedure is identified, the next step in the laboratory evaluation is to rule out the presence of occult heparin contamination. The most common cause of an unexplained prolonged APTT in a hospitalized patient is heparin (Fig. 1).

The presence of heparin may be easily identified by using a thrombin time or reptilase time. Heparin may also be neutralized using a cation exchange resin or protamine sulfate. However, the addition of substances to

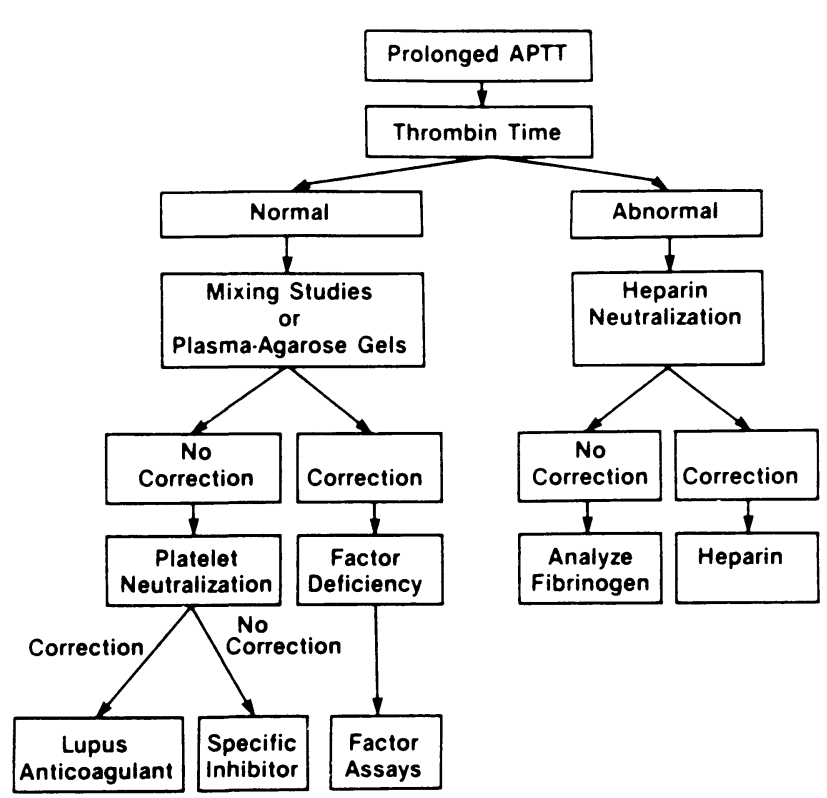

FIG. 1. Approach to prolonged APTT. 
neutralize heparin will interfere with further coagulation testing.

Once heparin is ruled out, the next step is a mixing study. Most laboratories utilize mixing studies of 1 part patient plasma to 1 part normal plasma. ${ }^{86}$ If there is a failure to correct the prolonged APTT, the diagnosis of a circulating inhibitor is established.

Mixing studies are often very difficult to interpret. In some instances, a 1:1 mix of LA and normal plasma may actually correct to within the normal range. Brandt et $\mathrm{al}^{82}$ observed this phenomenon on $16 \%$ of LA plasmas. Although this occurred more often in the case of borderline APTTs, it was also observed with very long patient baseline APTTs. Conventional wisdom has relied on the identification of LA by an immediate effect (that is, LAs do not require incubation to demonstrate maximal anticoagulant activity). In contrast, Factor VIII inhibitors often exhibit a time dependence. In most instances, the Factor VIII inhibitors with low titer will have such a pattern. Triplett et $\mathrm{al}^{21}$ were the first to stress the incidence of a time-dependent pattern with LA. In a subsequent study, Brandt et $\mathrm{al}^{82}$ found that 10 to $15 \%$ of LA showed a clear-cut time-dependent inhibition and an additional 15 to $20 \%$ showed a borderline timedependent prolongation. Lazarchick et $\mathrm{al}^{83}$ also found a $15 \%$ incidence of time dependency LA. Subsequently, Silberman et $\mathrm{al}^{87}$ also found a frequency of $40 \%$ timedependent LA (10 of 25). Clyne et al ${ }^{88}$ also found a frequency of $40 \%$ ( 21 of 52 ) in a retrospective study of LA. ${ }^{88}$ These three recent studies emphasize the necessity of time-dependent mixing studies in the evaluation of prolonged APTTs. In the Clyne study, $8 \%$ of cases would have been missed if only immediate mixing studies had been performed.

The evaluation of a minimally prolonged APTT (for example, less than $7 \mathrm{sec}$ above the upper limit of the normal range) is frequently misleading because it is often difficult to distinguish "correction" from "dilution" of inhibitor effect. When evaluating such plasmas, a mixture of 4 parts patient to 1 part normal is more sensitive to the presence of an inhibitor. ${ }^{89}$

Occasionally, mixing studies will yield a paradoxical accentuation of the patient's prolonged APTT or other screening tests. An unidentified factor that is present in normal plasma and responsible for this effect has been termed the "lupus cofactor.",90 This cofactor effect is most commonly seen when a $4: 1$ patient to normal mix is used. Also low concentrations of phospholipids will accentuate the "cofactor.",91 Jude et al ${ }^{27}$ also noted an apparent sensitivity of the lupus cofactor effect to the choice of activator in the APTT reagent. Reagents with ellagic acid apparently do not identify the "cofactor effect."

In cases in which the prolonged screening test is only minimally outside the upper limit of the normal range, mixing studies may be inconclusive. In these cases, the use of plasma-agarose gel is very helpful. ${ }^{92}$

\section{Confirmatory Procedures}

Following the identification of an inhibitor, it must be characterized. LA must be differentiated from specific inhibitors that are associated with clinical bleeding. A variety of tests have been proposed to identify LA. These tests have relied on two basic approaches: Either increasing the amount or altering the configuration of the phospholipid in the test system to bypass or neutralize the LA or decreasing the phospholipid concentration to accentuate the LA effect (Table 6).

The tissue thromboplastin inhibition (TTI) test is the most commonly used test to confirm the diagnosis of LA. ${ }^{93}$ Unfortunately, the TTI test is not specific for LA; consequently, reliance on the TTI test as a diagnostic procedure is unfounded. ${ }^{80,94}$ False-positive results may be seen with specific factor inhibitors (such as Factor VIII inhibitors), factor deficiencies, and with anticoagulant therapy. One study suggested that $40 \%$ of normal persons will have an abnormal TTI test. ${ }^{94}$ Recently, Liu and colleagues ${ }^{95}$ reported on a modified dilute thromboplastin inhibition test. ${ }^{95}$ They used varying dilutions of human brain thromboplastin and a platelet neutralization procedure to increase the specificity of the TTI. Using this approach, their system identified all LA with no false-positive results.

The dRVVT is also used as a confirmatory procedure for LA. ${ }^{96}$ The dRVVT appears to be sensitive to the presence of LA and in several studies has been utilized as both a screening procedure as well as a confirmatory test. In some patients who are receiving immunosuppressive therapy, the APTT will return to normal, but the dRVVT will remain prolonged. ${ }^{96}$

The KCT has been a useful test to identify and characterize LA. ${ }^{85,97}$ The KCT may be used to evaluate patients further with minimally prolonged APTTs or in patients with clinical findings of the phospholipid anti-

\section{TABLE 6. Confirmatory Procedures to Identify LA}

\footnotetext{
Test systems with decreased phospholipid

Tissue thromboplastin inhibition (TTI) ${ }^{93}$

Dilute Russell viper venom time ${ }^{96}$

Kaolin clotting time ${ }^{85}$

Dilute phospholipid APTT ${ }^{104}$

Test systems with increased phospholipid

Platelet neutralization procedure ${ }^{80}$

High phospholipid APTT ${ }^{102}$

Rabbit brain neutralization ${ }^{94}$

Phosphatidylserine liposome APTT ${ }^{84}$

Hexagonal phospholipid neutralization ${ }^{18}$
} 
body syndrome in whom an APTT is normal. The KCT may be used on patient plasma alone or on mixtures of patient and normal plasma. Several different patterns have been described when mixtures of patient and normal plasmas are used. ${ }^{85,91}$ An additional advantage of the KCT is its reliability in identifying LA in patients receiving warfarin. Disadvantages of the KCT are the requirement for filtered plasma and the fact that it is a manual procedure.

The platelet neutralization procedure (PNP) is based on the ability of platelets to bypass or significantly correct in vitro coagulation abnormalities. ${ }^{80}$ In early studies, platelets activated by adenosine diphosphate, collagen, or inophore (A23187) were utilized. ${ }^{98}$ Subsequently, the use of washed freeze-thawed platelets proved to be effective in significantly correcting the inhibitor effect of LA. In a recent study by Kornberg et al ${ }^{99}$ the PNP was compared with the TTI test and KCT index. The PNP was positive in $98 \%$ of the 48 patients, whereas the TTI test was positive in $79 \%$ and the KCT index in 77\%. Thus, the PNP appears to be the most sensitive of the confirmatory tests. ${ }^{99}$ Lesperance et al ${ }^{100}$ also found the PNP to be the most sensitive confirmatory test in their study. The properties of the platelet preparations or phospholipids used in neutralization or bypass procedures are of great importance. In an evaluation of 20 patients with LA, Dayton et $\mathrm{al}^{101}$ used freeze-thawed platelets, a commercial source of platelet extract (platelet extract reagent, BioData Corp.) and a concentrated solution of standard APTT reagent. The PNP using freeze-thawed platelets was positive in 20 of 20 patients, whereas the platelet extract reagent was positive in 9 of 20 and the concentrated APTT reagent in 5 of 20.

A variety of additional tests have been described, including the high phospholipid APTT of Clyne et al, ${ }^{102}$ the rabbit brain neutralization of Rosove et al, ${ }^{94}$ and the phosphatidylserine (PS)-liposome APTT of Kelsey et al. ${ }^{84}$ As mentioned earlier, the hexagonal phospholipid neutralization procedure of Rauch et $\mathrm{al}^{18}$ may prove to be the most specific test for LA. In a recent report, Rauch and Janoff ${ }^{103}$ evaluated ten LA plasma samples from patients with SLE, six plasmas containing specific anticoagulants, and five factor-deficient plasmas. They used a preincubation step using hexagonal phase PE and a dilute APTT assay. The hexagonal PE correctly identified all LA plasmas and was negative with samples containing specific inhibitors or factor deficiencies.

When factor assays are performed on LA plasma, the factors of the proximal intrinsic pathway are most commonly affected. ${ }^{105}$ Typically, Factors XII and XI are more affected than Factors VIII and IX. With dilution of the patient's plasma, the apparent factor activity will increase. This lack of parallelism of the factor assay curves is typical of plasma containing an inhibitor. Fac- tor assays performed using synthetic substrates are usually not affected by the presence of LA.

\section{Immunologic Assays: Phospholipid Antibody Test}

In 1983, Harris et $\mathrm{al}^{67}$ developed a solid phase radioimmunoassay for ACA. ${ }^{67}$ This assay is 200 to 400 times more sensitive than the standard VDRL. Subsequently, it was found that other negatively charged phospholipids, such as PS, PI, and phosphatidic acid (PA) could also be used as antigen in this assay enzyme-linked immunosorbent assay [ELISA] or radioimmunoassay [RIA]. ${ }^{13}$ Thus, a more generic term "antiphospholipid antibodies" was introduced. These antibodies have been associated with the same clinical complications seen in association with LA. Harris ${ }^{106}$ proposed the concept of an "antiphospholipid antibody syndrome," which would include patients with APA whether or not a LA is present (Table 7).

In most early studies, patients with LA had APA. ${ }^{107,108}$ However, there is considerable heterogeneity with approximately $30 \%$ of LA patients having no associated APA. ${ }^{13,100}$

Commercial sources of ELISA assays for APA are now available. These kits use either cardiolipin or a mixture of negatively charged phospholipids as antigen. An APA assay should be a part of the laboratory evaluation of any patient with clinical findings suggestive of the phospholipid antibody syndrome.

\section{TREATMENT}

The presence of LA or APA in an asymptomatic patient is not an indication for treatment. Although these

TABLE 7. Proposed Criteria for Antiphospholipid Antibody Syndrome*

\begin{tabular}{ll}
\hline Clinical $\dagger$ & Laboratory $\dagger$ \\
\hline Venous thrombosis & $\begin{array}{l}\text { IgG anticardiolipin antibody }(>10 \mathrm{GPL} \\
\text { units }) \ddagger\end{array}$ \\
Arterial thrombosis & $\begin{array}{l}\text { Positive lupus anticoagulant test§ } \\
\text { Recurrent fetal loss }\end{array}$ \\
Thrombocytoxemia & $\begin{array}{l}\text { IgM anticardiolipin antibody }(>10 \mathrm{MPL} \\
\text { units and positive LA test }\end{array}$ \\
\hline
\end{tabular}

* From Harris. ${ }^{106}$ Reprinted with permission.

$\uparrow$ Patients with the APA syndrome should have at least one clinical and one laboratory finding during the disease. The APA test should be positive on at least two occasions more than 8 weeks apart.

$\ddagger$ GLP and MPL refer to IgG and IgM phospholipid antibodies. The units refer to the standards proposed by Harris et $\mathrm{al}^{16}$ at the second International Workshop on phospholipid antibodies (April 4, 1986). $\S$ The lupus anticoagulant should be confirmed by correction of the prolonged clotting studies with freeze-thawed platelets (platelet neutralization procedure) 
patients may have an increased risk of thrombosis, available laboratory evaluation is not able to subdivide patients with APA/LA into high- or low-risk groups. ${ }^{13}$ There is some evidence to suggest that patients with IgG APA of high titer represent a high-risk group. ${ }^{106,109}$ However, other studies have not confirmed these findings. ${ }^{13}$ The presence of APA/LA in patients who are undergoing major surgery or prolonged confinement to bed would warrant the use of low-dose heparin prophylaxis (5000 U twice daily subcutaneously).

Patients with LA or APA who present with arterial or venous thrombosis are treated initially with heparin and then oral anticoagulation. Although corticosteroids may lead to normalization of the APTT, they are not an effective means of preventing recurrent thrombosis in patients with APA/LA. ${ }^{110}$

Lubbe et al ${ }^{111}$ were the first to treat young women with LA and a history of spontaneous abortion with prednisone (40 to $60 \mathrm{mg} /$ day) and low-dose aspirin $(75 \mathrm{mg}$ / day).${ }^{58,111}$ Although corticosteroids are not without complications, this regimen has proved effective in many cases. Other forms of therapy that have been described include intravenous immunoglobulin, heparin, plasma exchange, and immunosuppressive agents. ${ }^{112-114}$

In order to resolve the questions surrounding the clinical management of pregnancies in women with APA, the Fetal Loss Subcommittee of the Kingston AntiPhospholipid Study Group has proposed a multicenter clinical trial to evaluate therapeutic management of this patient group. ${ }^{115}$

\section{REFERENCES}

1. Hougie C: Circulating anticoagulants. In Poller L Ed: Recent Advances in Blood Coagulation, vol. 4. Churchill Livingstone, Edinburgh, 1985, pp. 63-90.

2. Feinstein DI: Acquired inhibitors against factor VIII and other clotting proteins. In: (Eds) Colman RW, J Hirsh, VJ Marder, EW Salzman: Hemostasis and Thrombosis, Basic Principles and Clinical Practice. JB Lippincott, Philadelphia, 1982, pp. 563-576.

3. Triplett DA: Antiphospholipid antibodies and recurrent pregnancy loss. Am J Reprod Immunol. In press.

4. Green D, K Lechner: A survey of 215 nonhemophilic patients with inhibitors to factor VIII. Thromb Haemost 45:200-203, 1981.

5. Shapiro SS, P Thiagarajan: Lupus anticoagulants. Prog Hemost Thromb 6:263-285, 1982.

6. Conley CL, RC Hartmann: A hemorrhagic disorder caused by circulating anticoagulant in patients with disseminated lupus erythematosus. J Clin Invest 31:621-622, 1952.

7. Feinstein DI, SI Rapaport: Acquired inhibitors of blood coagulation. Prog Hemost Thromb 1:75-95, 1972.

8. Bowie EJW, JH Thompson, CA Pascuzzi, CA Owen Jr.: Thrombosis in systemic lupus erythematosus despite circulating anticoagulant, J Lab Clin Med 62:416-430, 1963.

9. Nilsson IM, B Astedt, U Hedner, D Berezin: Intrauterine death and circulating anticoagulant. "Antithromboplastin." Acta Med Scand 197:153-159, 1975
10. Laurell AB, IM Nilsson: Hypergamma-globulinaemia, circulating anticoagulant, and biological false positive Wasserman reaction: A study of 2 cases. J Lab Clin Med 49:694-707, 1975.

11. Thiagarajan P, SS Shapiro, L DeMarco: Monoclonal immunoglobulin M coagulation inhibitor with phospholipid specificity; Mechanism of a lupus anticoagulant. J Clin Invest 66:397-405, 1980.

12. Harris EN, S Loizou, H Englert, G Derue, JK Chan, AF Gharavi, GRV Hughes: Anticardiolipin antibodies and lupus anticoagulant. (Letter.) Lancet 2:1099, 1984.

13. Triplett DA, JT Brandt, KA Musgrave, C Orr: Relationship between lupus anticoagulants and antibodies to phospholipids. JAMA 259:550-554, 1988.

14. Ankri A, MC Boffa, T Bienvenue, B Zalc: Study of the antiphospholipid specificity of lupus anticoagulants. Xth International Congress of Thrombosis, The Mediterranean League Against Thromboembolic Diseases. Athens, Greece, May 22-27, 1988. (Abstr. 126).

15. Harris EN, AE Gharavi, A Tincani, JKH Chan, H Englert, P Mantelli, F Allegro, G Ballestrieri, GRV Hughes: Affinity purified anticardiolipin and anti-DNA antibodies. J Clin Lab Immunol 17:155-162, 1985.

16. Pengo V, P Thiagarajan, SS Shapiro, MJ Heine: Immunological specificity and mechanism of action of $\operatorname{IgG}$ lupus anticoagulants. Blood 70:69-76, 1987.

17. Janoff AS, J Rauch: The structural specificity of antiphospholipid antibodies and autoimmune disease. Chem Phys Lipids 40:315$332,1986$.

18. Rauch J, M Tannenbaum, H Tannenbaum, H Ramelson, PR Cullis, CPS Tilcok, MJ Hope, AS Janoff: Human hybridoma lupus anticoagulants distinguish between lamellar and hexagonal phase lipid systems. J Biol Chem 267:9672-9677, 1986.

19. Corless JM, MJ Costello: Paracrystalline inclusions associated with the disk membrane of frog retinal rod outer segments. Exp Eye Res 32:217-228, 1981.

20. Buchheim LO, D Drenckhahn, R Lullmann-Rauch: Freeze fracture studies of cytoplasmic inclusions occurring in experimental lipoidosis as induced by amphiphilic cationic drugs. Biochim Biophys Acta 575:71-80, 1979.

21. Triplett DA, JT Brandt, RL Maas: The laboratory heterogeneity of lupus anticoagulants. Arch Pathol Lab Med 109:946-951, 1985.

22. Regan MG, H Lackner, S Karpatkin: Platelet function and coagulation profile in lupus erythematosus; studies in 50 patients. Ann Intern Med 81:462-468, 1974.

23. Zetterström R, G Berglund: Systemic lupus erythematosus in childhood: A clinical study. Acta Paediatr 45:189:204, 1956.

24. Petri M, M Rheinschmidt, Q Whiting-O'Keefe, D Hellmann, L Corash: The frequency of lupus anticoagulants in system lupus erythematosus. Ann Intern Med 106:524-531, 1987.

25. Orris DJ, JH Lewis, JA Spero, U Hasiba: Blocking coagulation inhibitors in children taking penicillin. J Pediatr 97:426-429, 1980.

26. Gastineau DA, FJ Kazmier, WI Nichols, EJW Bowie: Lupus anticoagulants; an analysis of the clinical and laboratory features of 219 cases. Am J Hematol 19:265-275, 1985.

27. Jude B, J Goudemand, I Dolle, C Caron, A Watel, C Tiry, A Cosson: Lupus anticoagulant: A clinical and laboratory study of 100 cases. Clin Lab Haematol 10:41-51, 1988.

28. Kitchens CS: Prolonged activated partial thromboplastin time of unknown etiology. Am J Hematol 26:38-45, 1988.

29. Zarrabi MH, S Zucker, F Miller, RM Derman, GS Romano, JA Hartnett, AO Varma: Immunologic and coagulation disorders in chlorpromazine treated patients. Ann Intern Med 91:194-199, 1979.

30. Bell WR, GR Boss, JS Wolfson: Circulating anticoagulant in the 
procainamide induced lupus syndrome. Arch Intern Med 137:1471-1473, 1977.

31. Zucker S, MH Zarrabi, GS Romano, F Miller: IgM inhibitors of the contact activation phase of blood coagulation in chlorpromazine-treated patients. Br J Haematol 40:447-457, 1978.

32. Singh AK, KPP Rao, J Kizer, J Lazarschick: Lupus anticoagulants in children. Ann Clin Lab Sci 18:384-387, 1988.

33. LeFrere JJ, D Gozin, J Modai, D Vittelog: Circulating anticoagulant in the acquired immunodeficiency syndrome. (Letter.) Ann Intern Med 107:429-430, 1987.

34. Bloom EJ, DI Abrams, G Rodgers: Lupus anticoagulant in the acquired immunodeficiency syndrome. JAMA 256:491-493, 1986.

35. Cohen AJ, TM Phillips, CM Kessler: Circulating coagulation inhibitors in the acquired immunodeficiency syndrome. Ann Intern Med 104:175-180, 1986.

36. Gold JE, R Zalusky: Lupus anticoagulant and AIDS. (Letter.) Engl J Med 314:1252-1253, 1986.

37. Taillan B, JG Fuzibet, C Roul, H Vinti, A Pesce, J Bayle, JP Bassuto, P Dujardin: Pathogenic significance of circulating anticoagulants in human immunodeficiency virus infection. Nouv Presse Med 18:1078, 1989.

38. Canoso RT, LI Zon, JE Groopman: Anticardiolipin antibodies associated with HTLV-III infection. Br J Haematol 65:495-498, 1987.

39. Mackie IJ, CB Colaco, SJ Machin: Familial lupus anticoagulants. Br J Haematol 67:359-363, 1987.

40. Exner T, S Barber, H Kronenberg, KA Rickard: Familial association of the lupus anticoagulant. Br J Haematol 45:89-96, 1980.

41. El-Roeiy A, N Gleicher, J Friberg, E Confino, A Dudkiewicz: Correlation between peripheral blood and follicular fluid autoantibodies and impact on in vitro fertilization. Obstet Gynecol 70:163$170,1987$.

42. Lechner K: Lupus anticoagulants and thrombosis. In: Verstaete M, J Vermylen, R Lijnen, J Arnout (Eds): Thrombosis and Haemostasis. Leuven University Press, Leuven, Belgium, 1987, pp. 525-547.

43. Egbert O: Inherited antithrombin deficiency causing thrombophilia. Thromb Diath Haemorrh 13:526-530, 1965.

44. Griffin JH, B Evatt, TS Zimmerman, AJ Kleiss, C Widman: Deficiency of protein $\mathrm{C}$ in congenital thrombotic disease. J Clin Invest $68: 1370-1373,1981$.

45. Sontheimer RD: The anticardiolipin syndrome. Arch Dermatol 123:590-595, 1987.

46. Carreras LO, SJ Machin, R Deman, G Defreyn, J Vermylen, B Spitz, A Van Assche: Arterial thrombosis, intrauterine death and "lupus" anticoagulant: Detection of immunoglobulin interfering with prostacyclin formation. Lancet 1:244-246, 1981.

47. Petraiuolo W, E Bovill, J Hoak: The lupus anticoagulant does not inhibit the release of prostacyclin from human endothelial cells. (Abst. 1429.) Thromb Haemost 58:390, 1987.

48. Rustin MHA, HA Bull, SJ Machin, DA Isenberg, MD Snaith, PM Dowd: Effects of the lupus anticoagulant in patients with systemic lupus erythematosus on endothelial cell prostacyclin release and procoagulant activity. J Invest Dermatol 90:744-748, 1988.

49. Angles-Cano E, Y Sultan, JP Clauvel: Predisposing factors to thrombosis in systemic lupus erythematosus. J Lab Clin Med 2:312-323, 1979 .

50. Galli M, S Cortelazzo, P Viero, G Finazzi, G deGaetano, T Barbui: Interaction between platelets and lupus anticoagulants. Eur J Haematol 41:88-94, 1988.

51. Cosgriff TM, BA Martin: Low functional and high antigenic antithrombin III level in a patient with the lupus anticoagulant and recurrent thrombosis. Arthritis Rheum 24:94-96, 1981.
52. Freyssinet JM, ML Wiesel, J Gauchy, B Boneu, JP Cazenave: An IgM lupus anticoagulant that neutralizes the enhancing effect of phospholipid on purified endothelial thrombomodulin activity-a mechanism for thrombosis. Thromb Haemost 55:309-313, 1986.

53. Cariou R, G Tobelem, J Caen: Lupus anticoagulant risk factor of thrombosis by inhibition of protein C activation. C R Acad Sci, Series III-Sciences de la Vie 303;118, 1986.

54. Comp PC, LE DeBault, NL Esmon, CT Esmon: Human thrombomodulin is inhibited by $\mathrm{IgG}$ from two patients with nonspecific anticoagulants. (Abst.) Blood 62 (Suppl 1): 299, 1983.

55. Freyssinet JM, JP Cazenave: Lupus-like anticoagulants modulation of the protein $\mathrm{C}$ pathway and thrombosis. Thromb Haemost 58:679-681, 1987.

56. Cines DB, A Tomaski, S Tannenbaum: Immune endothelial-cell injury in heparin-associated thrombocytopenia. N Engl J Med 316:581-589, 1987.

57. Soulier RP, MC Boffa: Avortements a repetition, thromboses et anticoagulant circulant antithromboplastine, Nouv Presse Med 9:859-864, 1980.

58. Lubbe WF, WS Butler, SJ Palmer, GC Liggins: Lupus anticoagulant in pregnancy. Br J Obstet Gynaecol 91:357-363, 1984.

59. Carreras LO, B Spitz, J Vermylen, A Van Assche: Lupus anticoagulant and inhibition of prostacyclin formation in patients with repeated abortion, intrauterine growth retardation and intrauterine death. Br J Obstet Gynaecol 88:890-894, 1981.

60. Lockshin MD, ML Druzin, S Goel, T Qamar, MS Magid, L Jovanovic, M Ferene: Antibody to cardiolipin as a predictor of fetal distress or death in pregnant patients with systemic lupus erythematosus. N Engl J Med 313:152-156, 1985.

61. Lockshin MD, T Qamar, ML Druzin, S Goel: Antibody to cardiolipin, lupus anticoagulant and fetal death. J Rheumatol 14:259$262,1987$.

62. de Wolf F, LO Carreras, P Moerman, J Vermylen, A Van Assche, M Ranaer: Decidual vasculopathy and extensive placental infarction in a patient with repeated thromboembolic accidents, recurrent fetal loss, and a lupus anticoagulant. Am J Obstet Gynecol 142:829-834, 1982.

63. Remuzzi G, D Marchesi, G Mecca, R Misian, E Rossi, MB Donati, $\mathrm{G}$ de Gaetano: Reduction of fetal vascular prostacyclin activity in preeclampia. Lancet 2:310, 1980.

64. Barbui T, S Cortelazzo, M Galli, FE Parazzini, E Rossi: Lupus anticoagulant and repeated abortions: A case control study. Thromb Haemost 58:232, 1987.

65. Howard MA, BG Firkin, DI Healy, SCC Choong: Lupus anticoagulant in women with multiple spontaneous miscarriage. Am J Hematol 26:175-178, 1987.

66. Tchobroutsky C, JD Clauvel, Y Sultan, F Danon, L Intrator, B Weil: Successful pregnancies in the antiphospholipid syndrome without prednisone. Clin Exp Rheumatol 6:213, 1988 (Abst.)

67. Harris EN, AE Gharavi, ML Boey, BM Patel, CG Mackworth Young, S Loizou, GRV Hughes: Anticardiolipin antibodies: Detection by radioimmunoassay and association with thrombosis in systemic lupus erythematosus. Lancet 2:1211-1214, 1983.

68. Boey ML, CB Colaco, AE Gharavi, KB Elkon, S Loizou, GRV Hughes: Thrombosis in systemic lupus erythematosus: Striking association with the presence of circulating lupus anticoagulant. Br Med J 287:1021-1023, 1983.

69. Lechner K: Acquired inhibitors in non-haemophilic patients. Haemostasis 3:65-93, 1974.

70. Weinstein C, MH Miller, R Axtens, R Buchanan, GO Littlejohn: Livedo reticulants associated with increased titers of anticardiolipin antibodies in systemic lupus erythematosus. Arch Dermatol 123:596-600, 1987.

71. Ingram SB, SH Goodnight Jr, RM Bennett: An unusual syndrome 
of a devastating noninflammatory vasculopathy associated with anticardiolipin antibodies: Report of two cases. Arthritis Rheum 30:1167-1172, 1987.

72. Grob JJ, JJ Bonerandi: Cutaneous manifestations associated with the presence of the lupus anticoagulant. J Am Acad Dermatol 15:211-219, 1986.

73. Englert H, MI Boey, G Derue, RG Hull, EN Harris, GRV Hughes: Degos' disease: Association with anticardiolipin antibodies and the lupus anticoagulant. Br Med J 289:576, 1984.

74. Haire WD: The acquired immunodeficiency syndrome and lupus anticoagulant. JAMA 252:3399, 1984.

75. Bajaj SP, SI Rapaport, DS Fierer, KD Herbst, DB Schwartz: A mechanism for the hypoprothrombinemia of the acquired hypoprothrombinemia-lupus anticoagulant syndrome. Blood 61:684-692, 1983.

76. Green D, C Hougie, FJ Kazmier, K Lechner, PM Mannucci, CR Rizza, Y Sultan: Report of the working party on acquired inhibitors of coagulation: Studies of the 'lupus' anticoagulant. Thromb Haemost 49:144-146, 1983.

77. Triplett DA, JT Brandt: Lupus anticoagulant: Misnomer, paradox, riddle epiphenomenon. Hematol Pathol 2:121-143, 1988.

78. Hughes GRV, EN Harris, AE Gharavi: The anticardiolipin syndrome. J Rheumatol 13:486-489, 1986.

79. Exner T: Comparison of two simple tests for the lupus anticoagulants. Am J Clin Pathol 83:215-218, 1985.

80. Triplett DA, JT Brandt, D Kaczor, J Schaeffer: Laboratory diagnosis of lupus inhibitors: A comparison of the tissue thromboplastin inhibition procedure with a new platelet neutralization procedure. Am J Clin Pathol 79:678-682, 1983.

81. Mannucci PM, MT Canciani, D Mari, P Meucci: The varied sensitivity of partial thromboplastin and prothrombin reagents in the demonstration of lupus-like anticoagulant. Scand J Haematol 22:423-432, 1979.

82. Brandt JT, DA Triplett, K Musgrave, C Orr: The sensitivity of different coagulation reagents to the presence of lupus anticoagulants. Arch Pathol Lab Med 111;120-124, 1987.

83. Lazarchick J, J Kizer: The laboratory diagnosis of lupus anticoagulants. Arch Pathol Lab Med 113:177-180, 1989.

84. Kelsey PR, KJ Stevenson, L Poller: The diagnosis of lupus anticoagulants by the activated partial thromboplastin time- the central role of phosphatidylserine. Thromb Haemost 52:172-175, 1984.

85. Exner T, KA Rickard, HA Kronenberg: A sensitive test demonstrating lupus anticoagulant and its behavioural patterns. Br J Haematol 40:143-151, 1978.

86. Ewing NP, CK Kasper: In vitro detection of mild inhibition of factor VIII in hemophilia. Am J Clin Pathol 77:749-752, 1982.

87. Silberman S, J Godwin, P Gattuso, C Beatty: Time-dependent circulating anticoagulants of the lupus type. ASCP/CAP Meeting, Fall, 1987, New Orleans.

88. Clyme LP, PF White: Time dependency of lupus-like anticoagulants. Arch Intern Med 148:1060-1063, 1988.

89. Raman SBK, SM Saeed: Lupus anticoagulant: Evaluation of sensitivity of various laboratory tests at different levels of APTT. (Abstr.): Am J Clin Pathol 90:508, 1988.

90. Loeliger EA; Prothrombin as cofactor of circulating anticoagulant in systemic lupus erythematous. Thromb Diath Haemorrh 8:237256, 1956.

91. Lo SCL, MJ Oldmeadow, MA Howard, BG Firkin: Comparison of laboratory tests used for identification of the lupus anticoagulant. Am J Hematol 30:213-220, 1989.

92. Cassidy PG, DA Triplett, FM LaDuca: Use of the agarose gel method to identify and quantitiate factor VIII:C inhibitors. Am J Clin Pathol 83:697-706, 1985.
93. Schleider MA, RL Nachman, EA Jaffe, M Coleman: A clinical study of the lupus anticoagulant. Blood 48:499-509, 1976.

94. Rosove MH, M Ismail, BJ Koziol, CK Kasper: Lupus anticoagulants: Improved diagnosis with a kaolin clotting time using rabbit brain phospholipid in standard and high concentrations. Blood 68:472-478, 1986.

95. Liu HW, KL Wong, CK Lin, WS Wong, PWT Tse, GTC Chan: The reappraisal of dilute tissue thromboplastin inhibition test in the diagnosis of lupus anticoagulant. Br J Haematol 72:229-234, 1989.

96. Thiagarajan P, V Pengo, SS Shapiro: The use of the dilute Russell viper venom time for the diagnosis of lupus anticoagulants. Blood 68:869-874, 1986.

97. Margolis J: The kaolin clotting time; a rapid one stage method for diagnosis of coagulation defects. J Clin Pathol 11:406-409, 1958.

98. Firkin BG, P Booth, L Hendrix, MA Howard: Demonstration of a platelet bypass mechanism in the clotting system using an acquired anticoagulant. Am J Hematol 5:81-82, 1978.

99. Kornberg A, L Silber, R Yona, S Kaufman: Clinical manifestations and laboratory findings in patients with lupus anticoagulants. Eur J Haematol 42:90-95, 1989.

100. Lesperance B, M David, J Rauch, C Infante-Rivard, GE Rivard: Relative sensitivity of different tests in the detection of low titer lupus anticoagulants. Thromb Haemost 60:217-219, 1988.

101. Dayton V, S Olson, L Peterson: Laboratory diagnosis of lupus anticoagulant: Comparison of two new methods to the platelet neutralization procedure. (Abstr.) Am J Clin Pathol 90:509, 1988.

102. Clyne LP, N Dainiak, R Hoffman, J Hardin: In vitro correction of anticoagulant activity and specific clotting factor assays in SLE. Thromb Res 18:643-655, 1980.

103. Rauch J, AS Janoff: Distinguishing plasma lupus anticoagulants from antifactor antibodies using hexagonal phase phospholipids. 53rd Annual Meeting of American College of Rheumatology, Cincinnati, Ohio, June 12-17, 1989.

104. Alving BM, CF Barr: The dilute phospholipid APTT: Evaluation of specificity for antibodies against cardiolipin and phosphatidylserine. (Abst. 1433.) Thromb Haemost 58:391, 1987.

105. Horellou MH, MH Aurousseau, MC Boffa, J Conard, ML Wiesel, M Samama: Biological and clinical heterogeneity of lupus and lupus-like anticoagulant in fifty-seven patients. J Med 18:199-217, 1987.

106. Harris EN: Syndrome of the black swan. (Editorial.) Br J Rheumatol 26:324-326, 1987.

107. Harris EN, GRV Hughes, AE Gharavi: Antiphospholipid antibodies: An elderly statesman dons new garments. J Rheumatol 14 (Suppl 13):208-213, 1987.

108. Branch DW, NS Rote, DA Dostal, JR Scott: Association of lupus anticoagulant with antibody against phosphatidylserine. Clin Immunol Immunopathol 42:63-75, 1987.

109. Asherson RA, EN Harris: Anticardiolipin antibodies in the detection of autoimmune disorders. Intern Med Specialist 8:73-88, 1987.

110. Derksen RHWM, D Bie: ma, BN Bouma, FHJG Meyling, L Kates: Discordant effects of prednisone on anticardiolipin antibodies and the lupus anticoagulant. (Letter.) Arthritis Rheum 29:1295, 1986

111. Lubbe WF, WS Butler, SJ Palmer, GC Liggins: Fetal survival after prednisone suppression of maternal lupus anticoagulant. Lancet 1:1361, 1983.

112. McVerry BA, R Spearing, A Smith: SLE anticoagulant: Transient inhibition by high dose immunoglobulin infusions. (Letter.) Br J Haematol 61;579-580, 1985. 
113. Rosove MH, K Tabsh, P Howard, N Wasserstrum, CR Brinkman, BJ Hahn, KC Kalunian: Heparin therapy for prevention of fetal wastage in women with anticardiolipin antibodies and lupus anticoagulants. (Abstr). Blood 70 (Suppl 1): 379, 1987.

114. Frampton G, JS Cameron, M Thom, S Jones, M Raftery: Successful removal of antiphospholipid antibody during pregnancy using plasma exchange and low-dose prednisolone. (Letter.) Lancet 2:1023-1024, 1987.
115. KAPS group plans major prospective studies on antiphospholipid antibodies, fetal loss, and thrombosis. Panlar Bulletin 3:9-11, 1988.

116. Harris EN, AE Gharavi, SP Patel, GRV Hughes: Evaluation of the anticardiolipin antibody test: Report of an International Workshop held 4 April 1986. Clin Exp Immunol 68:215-222, 1987. 